\title{
Contribuições da neurociências para a educação matemática de uma pessoa com necessidades educativas especiais intelectivas
}

\author{
Tania Elisa Seibert* \\ Claudia Lisete Oliveira Groenwald**
}

Resumo

Apresenta-se, neste artigo, um recorte de uma investigação de cunho qualitativo, do tipo estudo de caso, realizada com um aluno com Espinha Bífida, implementando uma sequência didática eletrônica individualizada, que tem como objetivo central qualificar a sua autonomia em Matemática. O aluno investigado, em 2012, tinha 14 anos e cursava a $7^{\mathfrak{a}}$ série do Ensino Fundamental. A questão norteadora desta investigação foi: um sujeito com Necessidades Educativas Especiais Intelectivas, de grau leve, pode superar dificuldades cognitivas em Matemática frente a uma sequência didática eletrônica? Ressalta-se a importância dos avanços da Neurociências no processo educacional de pessoas com Necessidades Educativas Especiais Intelectivas, a multimodalidade de estímulos oferecidos pela Tecnologia de Informação e Comunicação e recortes dos resultados da experiência realizada entre 2010 e 2012, com encontros semanais entre pesquisadores e o aluno, que apontam evolução frente aos conceitos matemáticos, como os de cardinalidade, ordinalidade, valor posicional do número, estrutura aditiva, compreensão de unidades de tempo, sistema monetário brasileiro e resolução de problemas que envolvem esses conceitos, em especial os que dizem respeito ao campo aditivo.

Palavras-chave: Neurociências; Educação Matemática; Necessidades Educativas Especiais Intelectivas.

\footnotetext{
* Doutoranda do Programa de Pós Graduação em Ensino de Ciências e Matemática (PPGECIM), Universidade Luterana do Brasil, Canoas, Rio Grande do Sul, Brasil.

** Professora doutra da Universidade Luterana do Brasil, Centro de Ciências Naturais e Exatas, Campus Canoas. Canoas, Rio Grande do Sul, Brasil.
} 


\section{Contributions of neurscience to mathematical education of one people with intellective special educational needs}

\section{Abstract}

This article presents a framework from a qualitative research, which is a case study, conducted with a student who has Spina Bifida, implementing an individualized electronic didactic sequence, which has as its central objective to qualify his autonomy in mathematics. The investigated student was 14 years old and attended the $7^{\text {th }}$ grade of elementary school in 2012. The guiding question of this research was: can a person with a mild level of Intellective Special Educational Needs overcome cognitive difficulties in Mathematics involving an electronic didactic sequence? We emphasize the importance of neuroscience advances in educational process of people with Intellective Special Educational Needs, the multimodality of stimuli offered by Information and Communication Technology and the frameworks from the experiment results carried out between 2010 and 2012, with weekly meetings between researchers and the student, which indicate an evolution related to mathematical concepts such as cardinality, ordinality, place value, additive structure, comprehension of units of time, Brazilian monetary system and resolution of problems involving these concepts, especially those related to the additive field.

Keywords: Neurosciences; Mathematics Education; Intellective Special Educational Needs.

\section{Introdução}

O sistema educacional, a partir a Lei no 9394/96, de dezembro de 1996, (BRASIL, 1996), deve atender pessoas com Necessidades Educativas Especiais (NEE), em classes de ensino regular, ampliando o direito de educação para todos, conforme proclamado na Constituição da República Federativa do Brasil (BRASIL, 1988). Ciente da necessidade de reformulação das escolas para incluir esses alunos, e em especial, nessa pesquisa, aqueles com Necessidades Educativas Especiais Intelectivas (NEEI), propôs-se investigar a contribuição da Neurociências nos processos de aprendizagem de conceitos Matemáticos e a implementação de uma sequência didática eletrônica (SDE) com situações de aprendizagem dos conceitos matemáticos, buscando uma melhor qualidade de vida.

Segundo Milheiro (2012), os domínios da vida dizem respeito à forma como as pessoas se organizam e incluem, entre outros, o lugar e a família, a profissão e a educação, o tempo livre e a relação com a comunidade, enquanto que os domínios de suporte são os aspectos individuais que estão relacionados com as responsabilidades e atividades de vida adulta abrangendo a saúde física, emocional e o desenvolvimento pessoal. A preparação e a orientação para a vida adulta passam pela inter-relação 
desses dois domínios, possibilitando uma maior qualidade de vida, de forma a manter maior independência, associada a condições materiais de vida, respeito, reconhecimento social e inserção no mundo do trabalho.

A Matemática insere-se, nesse processo, pela necessidade do desenvolvimento de conceitos, que são fundamentais para a autonomia, destacando a compreensão do sistema monetário, de localização no tempo e da resolução de problemas que fazem parte do cotidiano. Para lidar com essas questões, é necessário que se compreendam conceitos, como o de número, do sistema de numeração decimal e das operações no conjunto dos Números Naturais.

Este artigo contempla a investigação de uma intervenção pedagógica cognitiva com um jovem de 14 anos, com NEEI, que possui dificuldades de aprendizagem em Matemática.

\section{Necessidades Educativas Especiais Intelectivas e a Neurociências}

Utiliza-se a denominação pessoas com Necessidades Educativas Especiais Intelectivas (NEEI) quando as necessidades educativas se referem ao processo de construção do conhecimento, à cognição (FIERRO, 2004).

Para Relvas (2009a, 2009b), essas pessoas distinguem-se das demais por apresentarem dificuldade de generalizar, classificar, abstrair e analisar, possuindo um ritmo mais lento para aprender. Segundo Ferreira, Dias e Santos (2011), é vital o reconhecimento de suas possibilidades em nível educacional e social e a adaptação do currículo escolar deverá respeitar o nível de aptidão desses, adequando-o ao seu perfil intraindividual.

Considerando-se o estudo das possibilidades de pessoas com NEEI modificarem as suas estruturas mentais, optou-se pelo estudo da Neurociências, em especial do Sistema Nervoso (SN), (responsável pela coordenação das atividades externas e internas do organismo, produzindo a integração e a homeostase do indivíduo) e do Sistema Nervoso Central (SNC), já que sua função é relacionar o indivíduo com o meio e consigo mesmo, captando os estímulos (frio, quente, emocional), interpretando-os e decodificando-os, realizando registros (memória) e elaborando respostas motoras ou emocionais relativas ao estímulo captado (conduta) (RELVAS, 2009a).

Entre os inúmeros conceitos relacionados à Neurociências, destacam-se alguns em função da importância dos mesmos em relação aos processos de aprendizagem.

a) Neurogênese: formação dos neurônios com sua estruturação e constituição completa, que se inicia, aos 30 dias de vida intrauterina, atingindo o máximo aos 3 meses de vida intrauterina (DOMINGUES, 2007). 
b) Neurônios: células individuais excitáveis do SN que veiculam as informações entre a periferia do SNC e entre regiões do SNC e se comunicam umas com as outras, estabelecendo, dessa forma, relações de acoplamento (por exemplo, neurônio A com o neurônio A') (DOMINGUES, 2007).

c) Sinaptogênese: processo de comunicação que ocorre entre os neurônios, propiciando as intercomunicações e inter-relações dos estímulos captados, formando as sinapses, que são os pontos de acoplamento e comunicação entre os neurônios (FIORI, 2008).

Segundo Lent (2004), a sinapse faz o papel do "chip" do SN, capaz não só de transmitir mensagens entre duas células, mas também de bloqueá-las ou modificá -las inteiramente, realizando um verdadeiro processamento de informação. O cérebro armazena fatos separadamente, entre neurônios, e a aprendizagem se dá quando estes são associados através das sinapses. Essa associação ocorre quando novos estímulos provenientes do meio, através dos sentidos, são propagados.

d) Mielinização: processo de formação da bainha de mielina, envoltório do axônio responsável pela proteção, velocidade de transmissão do impulso nervoso e maturação neural. Tem grande influência na atuação das diferentes fases maturativas do indivíduo (RELVAS, 2009a).

e) Arborização dos dendritos e axônios: formação dos ramos dos neurônios e axônios (dendritos) e seus colaterais, que servem como atalhos, facilitando a intercomunicação entre os neurônios. Os dendritos captam os estímulos recebidos, tornando os neurônios aptos e atentos para captar a periferia do corpo. Os colaterais possibilitam aos neurônios estabelecer relações entre os estímulos, tornando o impulso nervoso mais rápido e associativo. Os estímulos captados não seguirão de uma forma somente linear como, $\mathrm{A} \rightarrow \mathrm{B} \rightarrow \mathrm{C}$, até atingir K. Através dos colaterais, poderão ser rapidamente associados e formar relações diretas como, por exemplo, $\mathrm{B} \rightarrow$ $\mathrm{K}$, proporcionando um pensamento ou uma percepção mais ampla de determinado ensinamento, com conclusões associativas e abrangentes, o que caracteriza a gnosia. (o conhecimento). A formação dessas estruturas está relacionada à estimulação adequada, tanto em intensidade quanto em tipo (DOMINGUES, 2007).

f) Plasticidade cerebral: é a denominação das capacidades adaptativas do SNC - sua habilidade para modificar sua organização estrutural própria e seu funcionamento. Permite o desenvolvimento de alterações estruturais em resposta à experiência e a estímulos repetidos. Existem vários mecanismos de plasticidade, sendo a sináptica a mais importante (RELVAS, 2007, 2009a).

O mecanismo de aprender está relacionado ao funcionamento do SNC, pois cada tipo de habilidade ou comportamento está relacionado a certas áreas particulares do cérebro. Há áreas habilitadas a interpretar estímulos que levam à percepção visual e auditiva, à compreensão, à capacidade linguística, à cognição, ao planejamento de ações futuras, inclusive de movimento, entre outros. Ensinar a uma pessoa uma habilidade nova implica maximizar o potencial de funcionamento de seu cérebro, isso 
porque aprender exige planejar novas maneiras de solucionar desafios, estimulando diferentes áreas cerebrais a trabalhar com a capacidade máxima (OLIVEIRA, 2005; RELVAS, 2009a).

O SNC, segundo Lent (2004) e Fiori (2008), comporta sete partes fundamentais: medula espinhal, bulbo, ponte, cerebelo, mesencéfalo, diencéfalo (tálamo e hipotálamo) e os hemisférios cerebrais (ou telencéfalo) (figura 1).

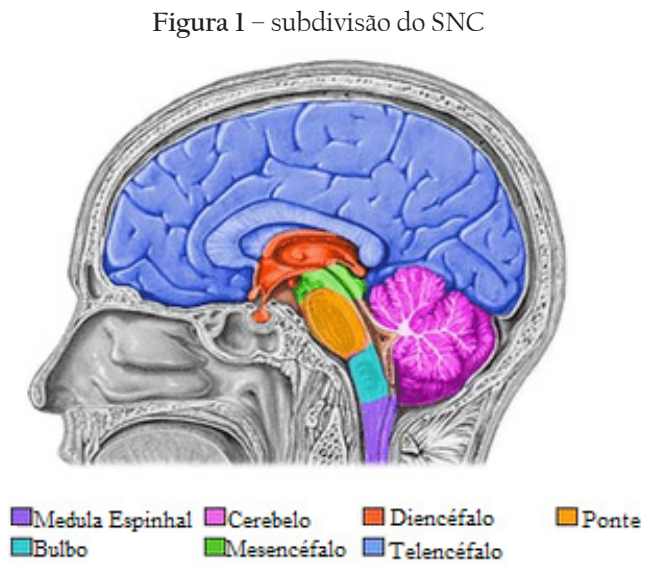

Fonte: http://psicologiaibmr2009.blogspot.com/2009/03/aula-1-funcoes-e-divisao-do-sistema.html.

O cérebro é constituído por dois hemisférios cerebrais e pelo diencéfalo. O tronco cerebral engloba o cérebro posterior e o cérebro médio; o cérebro anterior engloba o córtex, o sistema límbico e os gânglios da base (FIORI, 2008).

Os dois hemisférios, o esquerdo e o direito, se diferenciam quanto às suas características e funções. O esquerdo se caracteriza por ser lógico, direto, linear, convergente, científico, concreto, matemático, jurídico, avaliativo, crítico. O direito por ser divergente, metafórico, simbólico, artístico, musical, idiossincrático, holístico, ajurídico, acrítico. A comunicação entre eles ocorre, através do corpo caloso e da comissura anterior. O corpo caloso é formado por um feixe de fibras, situadas na região medial do encéfalo, entre os dois hemisférios, projetando-se para o interior desses, realizando a integração e a troca de informações (OLIVEIRA, 2005; HOWAR-JONES, 2012).

As vias sensitivas, que trazem os impulsos provenientes do corpo (ascendentes ou aferentes) ${ }^{2}$ e as vias motoras, que trazem as ordens elaboradas no córtex (descendentes ou eferentes) ${ }^{3}$, não trafegam direto, mas cruzam-se na região posterior do tronco encefálico. Portanto, os estímulos provenientes da parte direita do corpo atingem o hemisfério esquerdo e vice versa. Somente os estímulos auditivos são captados nos dois hemisférios ao mesmo tempo (OLIVEIRA, 2005). 
O córtex (camada mais externa dos hemisférios) contêm as seis camadas de corpos neuronais, os dendritos, uma parte dos axônios e as terminações de neurônios. Ocupa os giros e o espaço no interior dos sulcos e das fissuras e constitui $80 \%$ do volume do cérebro. Os sulcos e as fissuras repartem cada um dos hemisférios cerebrais em quatro grandes lobos (figura 2): o sulco lateral separa o lobo frontal do temporal, o sulco central separa o lobo frontal do parietal, o sulco parieto-occipital separa o lobo parietal do occipital. A fissura inter-hemisférica separa os hemisférios cerebrais direito e esquerdo, os quais são conectados pelo corpo caloso e a comissura anterior, grande feixe de fibras nervosas mielinizadas que liga cada região de um hemisfério à região equivalente do outro hemisfério (FIORI, 2008).

Figura 2 - lobos cerebrais.

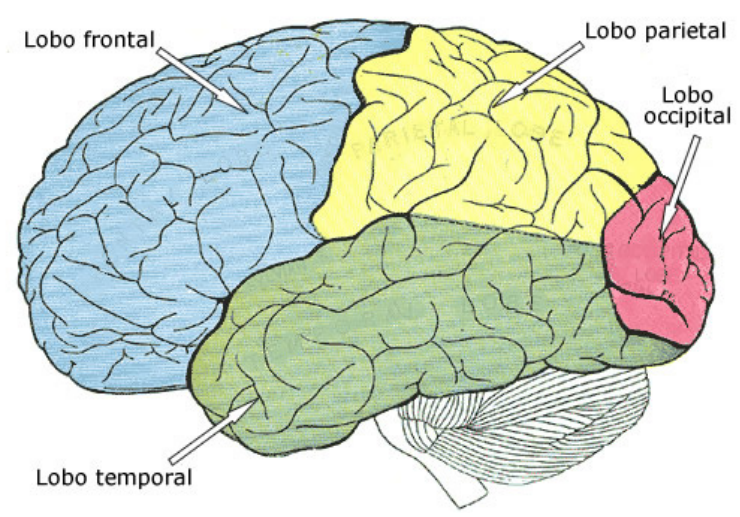

Fonte: http://static.infoescola.com/wp-content/uploads/2010/01/lobos-cerebrais.jpg.

A cada um dos lobos podem ser associadas funções principais descritas a seguir, segundo Oliveira (1999, 2005), Fiori (2008), Relvas (2009a) e Araújo (2011).

a) Lobo occipital (córtex visual): está localizado na parte posterior do cérebro e contém as áreas de tratamento visual. Define a capacidade de compreender o que se vê e é subdividido em pequenas áreas especializadas nas suas funções, por exemplo, processar a visão da cor, do movimento, da distância, etc.

b) Lobo parietal: localiza-se na parte superior do cérebro e interpreta os estímulos sensoriais provenientes do corpo, sendo responsável pela combinação das impressões relacionadas à forma, à textura, ao peso, a orientação espacial e a percepção da posição das partes do corpo. Parte desse lobo é uma grande área de associação de estímulos dos demais lobos: é o lugar em que os lobos "conversam" entre si e trocam informações. As lesões nesse lobo resultam em perda do conhecimento geral, inadequação do reconhecimento de impulsos sensoriais e falta de interpretação das relações espaciais.

c) Lobo temporal: contém as áreas de tratamento auditivo. Está localizado nas partes laterais de cada hemisfério. É a estrutura central responsável pelo gerenciamento da memória e do processamento dos estímulos audi- 
tivos. É extremamente importante para o aprendizado, pois parte do lobo temporal integra o sistema límbico (emoções), o hipocampo (memória), o uncus (olfato), a área de Wernicke (área de expressão sensória ou de interpretação) pelo reconhecimento da palavra, compreensão e (produção do discurso), possuindo interconexões com a área frontal da linguagem (Broca), responsável pela articulação da palavra.

d) Lobo frontal: contém as áreas motoras e caracteriza-se por seu papel primordial nas funções executivas, nas habilidades motoras (escrever, tocar instrumentos musicais, nas expressões faciais) e nas funções cognitivas. A faculdade de planejamento, representação mental do mundo externo, produção da fala, comportamento emocional e personalidade também são atribuídos ao lobo frontal. Incluem, também, o pensamento abstrato e criativo, a fluência do pensamento e da linguagem, respostas afetivas e capacidade para ligações emocionais, julgamento social, atenção seletiva, resolução de problemas, emoção e raciocínio.

Relvas $(2007,2012)$ destaca que os avanços da Neurociências têm contribuído para o entendimento dos processos de cognição. No entanto, salienta que o cérebro necessita de estímulos, pois as células nervosas, quando excitadas, produzem neutrofinas: moléculas que estimulam seu crescimento e reação. O princípio básico é fugir da rotina, pois o cérebro cria hábitos e funciona automaticamente. Destaca que as aprendizagens perpassam pelas sinapses, pelas conexões neurais e pelo envolvimento e interação no ambiente social, salientando que o cérebro é plástico e, por isso, capaz de sofrer modificações.

Assim, a aprendizagem é o processo pelo qual o cérebro reage aos estímulos do ambiente, ativando sinapses, tornado-as mais "intensas". Como consequência, essas se constituem em circuitos que processam as informações, com capacidade de armazenamento molecular. A formação de padrões de atividade neural corresponde a "estados e representações mentais". O ensino bem sucedido provoca alteração na taxa de conexão sináptica, afetando a função cerebral, dependendo da natureza do currículo, da capacidade do professor, do método de ensino, do contexto da sala de aula, da família e da comunidade (INÁCIO, 2011).

A cada nova experiência do indivíduo, redes de neurônios são rearranjadas, outras sinapses são reforçadas e múltiplas possibilidades de respostas ao ambiente tornam-se possíveis. O número e a qualidade das sinapses em um neurônio pode variar, entre outros fatores, pela experiência e aprendizagem, demonstrando a capacidade plástica do SN (RELVAS, 2007, 2012).

Kandel (apud Relvas 2009a) chamou atenção para o fato de a plasticidade cerebral ser dependente dos estímulos ambientais e, por conseguinte, das experiências vividas pelo indivíduo. Logo, as mudanças ambientais interferem na plasticidade cerebral e, consequentemente, na aprendizagem. Define a aprendizagem como modificação do SNC, mais ou menos permanente, quando o indivíduo é submetido a estímulos/experiências de vida, que vão se traduzir em modificações cerebrais, observando que as alterações plásticas são as formas pelas quais se aprende. 
Os neurônios e as células gliais têm capacidade de regeneração até de estruturas nervosas adultas. A relação entre experiência e estímulo constitui o principal pilar para a regeneração dessas células, por isso os exercícios cuja cognição seja bem estimulada são importantes, tanto na repaginação do movimento cerebral de aprender, quanto na recuperação de alunos aparentemente desestimulados. Utilizando-se estratégias didáticas diferenciadas, estabelece-se a recontextualização dos indivíduos, mesmo que vagarosamente. Portanto, o conceito de plasticidade cerebral deve ser aplicado à educação, considerando a tendência do SN em se ajustar diante das influências ambientais que se dão durante o desenvolvimento infantil ou na fase adulta, restabelecendo e restaurando funções desorganizadas por condições patológicas, através da capacidade de criar respostas compensatórias (RELVAS, 2009a, 2012).

Além do aspecto de regeneração das estruturas nervosas, Howard-Jones (2012) faz referência ao fato de que o nascimento de novos neurônios também acontece na adolescência, particularmente nos lobos frontal e parietal, nos quais as podas sinápticas não iniciam antes da puberdade. Uma segunda mudança envolve a mielinização, que melhora a eficiência com a qual a informação é comunicada no cérebro. Nos lobos frontal e parietal, a mielinização aumenta nessa faixa de idade e continua, com menor intensidade, na vida adulta, favorecendo um aumento na velocidade com a qual a comunicação neural ocorre nessas áreas.

Outro fator importante nos processos de aprendizagem, segundo Lent (2004), diz respeito às áreas límbicas, envolvidas com as funções motivacionais. Levine (2003) classifica a motivação em dois tipos: interna e externa. A interna diz respeito ao desejo genuíno de enfrentar e realizar algo em interesse próprio, enquanto a externa necessita de algum incentivo externo associado. Destaca que o sucesso alimenta a motivação para aprender, o desejo de absorver e suportar os riscos que acompanham os novos e crescentes desafios ao cérebro, os quais fazem parte do processo de aprendizagem de qualquer ser humano. A motivação faz com que o sucesso seja maior. O fracasso abafa a motivação, e a falta dela faz com que o fracasso seja constante.

Em algumas crianças, conforme Levine (2003), a motivação é espontânea. Outras não vivenciam a motivação de jeito nenhum, e algumas simplesmente desistem, pois fatores além do seu controle determinam essas situações. Acreditar não ser inteligente, ou ter nascido para o fracasso, ou ser uma pessoa infeliz eliminará qualquer motivação e erradicará todo o incentivo escolar. Um indivíduo fica motivado quando considera o objetivo atraente e acredita que possa atingí-lo. Quando uma aptidão acadêmica ainda não é automática e precisa de muito tempo e energia, a motivação pode se extinguir.

Em relação a Matemática e a Neurociências, Bravo (2010) afirma que segundo a teoria de localização cerebral, a atividade Matemática se apresenta, em maior medida, no lobo frontal e parietal do cérebro, pois aí se registra um maior consumo de energia com a atividade Matemática, nas regiões denominadas sulco intraparietal e inferior. Para o autor, é a região parietal inferior que controla o pensamento matemático e a capacidade cognitiva viso-espacial. Porém, salienta que as tarefas complexas 
do processamento matemático se devem à orientação simultânea de vários lobos do cérebro, pois a simples resolução de um problema que necessita de uma operação aritmética requer habilidades verbais, espaciais, conceituais, aritméticas e raciocínio.

\section{Sequência didática eletrônica e as necessidades Especiais Educativas Intelectivas}

Para investigar a utilização de uma Sequência Didática Eletrônica (SDE) com conceitos matemáticos que objetivam qualificar a autonomia de pessoas com NEEI, optou-se por uma pesquisa qualitativa, do tipo estudo de caso, com um jovem de 14 anos (aqui chamado de G), que em 2012 frequentava a 7ª série do Ensino Fundamental, com Espinha Bífida. Segundo laudo avaliativo neuropsicológico, emitida por Coelho e Kaefer (2012), esse apresenta um desempenho intelectual global classificado como nível limítrofe em função dos seus escores de QI e de Índices: QI Verbal: 80; QI Executivo: 77; QI Total: 76; Compreensão verbal: CV. 85; Organização perceptual: OP. 86; Resistência à distração: RD. 61; Velocidade de processamento: VP. 6l. A avaliação neurofisiológica, segundo Farina (2012), demonstra atraso na velocidade de processamento cerebral da informação, conforme medido pelo P $300,{ }^{4}$ associado a sinais sugestivos de presença de menor recrutamento neuronal para a tarefa do teste. A dificuldade de aprendizagem é secundária e advém dos fatores neurológicos e emocionais que, nesse momento, afetam a sua cognição. Conforme pareceres das escolas, $G$ tem dificuldades de aprendizagem, especialmente, em Matemática. A intervenção pedagógica cognitiva foi realizada com encontros semanais, totalizando 72 sessões de estudo (114h), entre março de 2010 e novembro de 2012.

A Espinha Bífida é uma malformação congênita do SNC, que se desenvolve no primeiro mês de gestação, durante a fase chamada de neurulação, e engloba uma série de malformações. Caracteriza-se pela formação incompleta da medula espinhal e das estruturas que protegem a medula. Essa doença ocasiona um defeito no fechamento das estruturas que formarão o dorso do embrião e que pode afetar não somente as vértebras, mas também a medula espinhal, meninges, o encéfalo e o corpo caloso. Essa malformação congênita atinge $0,5 \%$ da população brasileira (AEBH, 2010).

Características comuns do fenótipo físico da Espinha Bífida são defeitos na medula espinhal, incapacidade de coordenação das extremidades inferiores e superiores, frequentemente associadas a uma significativa paraplegia e mobilidade reduzida, causadas por danos no lóbulo parietal, hidrocefalia e deficiências visos-espaciais. Já, o fenótipo neural aponta para uma interrupção significativa do desenvolvimento cerebral, ocasionando danos, nas habilidades acadêmicas e cognitivas, relacionados com aspectos perceptivos, atenção e memória. Estudos comprovam um padrão nas deficiências matemáticas associadas com a Espinha Bífida, observáveis, também, na vida adulta, tendo importantes implicações futuras de emprego e na qualidade de vida dos adultos (BARNES, CHANT e LANDRY, 2005).

Os estudos de Dennis e Barnes (2002) ressaltam que crianças com Espinha Bífida têm dificuldades em Matemática semelhantes às dificuldades comuns a outras síndromes, como problemas com a recuperação de fatos matemáticos, com 
o desenvolvimento e utilização de procedimentos matemáticos e com a memória de trabalho. Destaca que sua independência funcional é restrita, pois não adquirem a numeracia necessária para fazer compras, manter uma conta bancária e são escassas as suas oportunidades de emprego.

A opção por uma SDE se dá em função de estudos, como os de Howard-Jones (2012), que apontam como importante o tipo de multimodalidade que a tecnologia pode oferecer, já que os estímulos multimodais produzem atividade cerebral extra, superior e acima daquela produzida ao se experimentar cada modo separadamente.

A SDE foi desenvolvida utilizando diferentes recursos: aplicativo $\mathrm{JClic}^{5}$ (exercícios e problemas), PowerPoint salvo em HTML (material de estudo) e jogos online.

\section{Refletindo}

Sobre a motivação demonstrada por $G$ frente às diferentes atividades, ressaltam-se alguns aspectos. Conforme Levine (2003), a motivação interna diz respeito ao desejo genuíno de enfrentar e realizar algo em interesse próprio. $\mathrm{Na}$ análise das sessões de estudo, fica claro que o desejo de enfrentar novas situações se deu em função do seu julgamento sobre a sua capacidade de resolvê-las. Frente à atividade, por exemplo, de números romanos ${ }^{6}$, mostrou-se muito ansioso e tentou de todas as formas não enfrentá-la, pois considerava impossível compreender esta numeração. Porém, nas atividades de números escritos por extenso, preocupação externada por ele como não compreensível, demonstrou desejo de enfrentá-las, pois se sentia apto a aprendê-las, dando indícios sobre a importância de apresentar atividades que estejam próximas da sua zona de desenvolvimento proximal. ${ }^{7}$

Destaca-se outros aspectos importantes, como o da motivação externa, ${ }^{8}$ apontada por Levine (2003) como sendo aquela que necessita de algum incentivo externo associado, o da necessidade de exercícios de memorização e de repetição em pessoas com NEEI, destacadas por Relvas (2009a), e da multimodalidade de estímulos que a tecnologia oferece (imagens, sons, escrita) apontados por Howard-Jones (2012), e que contribuíram no processo de aprendizagem dos conceitos matemáticos de $G$.

Sobre a evolução frente aos conceitos matemáticos, destacam-se alguns momentos importantes. Sobre o conceito de cardinalidade, no início da intervenção, $G$ não percebia visualmente pequenas quantidades, contava de forma desorganizada, quando os números estavam escritos por extenso não os reconhecia, não conhecia o significado das palavras antecessor e sucessor, confundia ordem crescente e decrescente, porém, no decorrer das sessões, demonstrou evoluções nestes conceitos. Quanto à ordinalidade $G$ não demonstrou a mesma evolução. 
Conforme Ramos (2009), o conceito de cardinalidade tem relação direta com o conceito de classificação e a ordinalidade está ligada à compreensão da seriação. Segundo o laudo de Coelho e Kaefer (2012) G apresenta um prejuízo significativo em seriação (em nível deficitário), o que pode justificar a dificuldade na compreensão do número ordinal.

Em relação à compreensão do número e do sistema de numeração decimal, quando da resolução de problemas, destaca-se as falas no $5^{\underline{0}}$ mês de intervenção.

G: Meu tio tem 48 anos [...] Existe algum cara com 48 anos?

P: Se existe uma pessoa com 48 anos? Por quê?

G: Porque ela não existe.

P: Pensou que já tinha morrido?

G: Sim.

P: Tu sabes que eu tenho 55.

G: (Pensa) Ah?

P: Então um dia já tive 48 anos.

Este diálogo demonstra que $G$ não compreendia o significado dos números, pois não percebeu que a idade de 55 anos é superior a de 48. Mas, no $21^{\circ}$ mês de intervenção, é possível perceber a evolução da compreensão desse conceito.

G: Se hoje eu tenho 13 anos e minha amiga tem 11 anos, quando eu tiver 40 ela vai ter...

P: Pensa! Quantos anos tu tens a mais que ela?

G: Dois. Então ela vai ter 38.

P: Isso mesmo.

G: Quando ela tiver 80 eu vou ter 82.

P: Tá certo. Fantástico.

Sobre a resolução de problemas do campo aditivo, na fase inicial da intervenção pedagógica cognitiva, $G$ resolvia, de forma mecânica, cálculos através de algoritmos, mas, ao resolver problemas da estrutura aditiva, optava pela operação que considerava adequada, em função das palavras mais, menos, total, juntar, ao todo. Essa situação foi evidenciada em problemas com perguntas do tipo "quanto a mais" ou "quanto a menos". No decorrer da intervenção, houve um progresso significativo em relação à compreensão das diferentes situações envolvidas no campo conceitual da adição. 
Quanto à compreensão do sistema monetário brasileiro, G mostrou-se ansioso, pois se sentia incapaz de compreendê-lo. Porém, solicitava atividades com dinheiro, porque compreendia a necessidade de conhecer o sistema monetário, afirmando que "vou ser um adulto pobre, porque não consigo entender". Sua principal dificuldade estava no reconhecimento das moedas e no fato de que "muitas moedas juntas" tem o valor de uma nota de papel.

G: Estou certo? (Junta 4 moedas de 50 centavos e compara com uma nota de 2 reais). Olha aqui.

\section{P: O que foi $G$ ?}

G: Essas valem igual à nota?

P: Sim, tem o mesmo valor.

G: É difícil de entender! Todas essas para uma.

Em outra sessão, $G$ realizou compras na Internet, tendo 70 reais para gastar. G demonstra entender "os preços", pois responde corretamente as questões de "mais ou menos", relacionando o valor dos objetos com o dinheiro que dispõe.

Percebeu-se um grande avanço quando questionado sobre preços dos produtos na Internet. Um brinquedo grande custava $\mathrm{R} \$ 86,00$ e os pequenos $\mathrm{R} \$ 43,00$. Questionado se poderia comprar dois pequenos pelo valor do grande, $G$ realizou a adição $(43+43)$ sem montar o algoritmo, utilizando apenas os dedos e adicionando unidade com unidade e dezena com dezena, afirmando que poderia comprar dois pequenos ou um grande.

Em uma situação de resolução de problemas, $G$ modifica a sua estratégia de resolução frente a uma situação de adição $(3+3+3)$, resolvendo-o com uma multiplicação ( 3 × 3). O grande avanço observado nesse episódio não se restringe ao resultado encontrado, mas sim, ao fato de utilizar a tabuada e o seu significado, de forma adequada, na resolução dos problemas.

Outro fato importante diz respeito ao cálculo mental. Aos poucos $G$ incorpora vários fatos numéricos e realiza os cálculos, deixando de lado o material concreto. Passa a montar algoritmos e resolvê-los de forma correta e inicia o processo de cálculo mental, que ele chama de "aventura".

\section{Considerações finais}

Destaca-se, como essencial, a evolução cognitiva de $G$ em relação à compreensão do número, ao sistema de numeração decimal, ao valor posicional dos algarismos, a notação e leitura dos números. Consideram-se estes conceitos fundamentais para o desenvolvimento da autonomia social de $G$ e sua preparação para a vida adulta. 
Pode-se afirmar que $G$, ao modificar a forma de resolução dos problemas (por exemplo, deixando de utilizar adições de parcelas iguais para utilizar o conceito de multiplicação), criou uma nova sinapse, pois fez uso de diferentes fatos e conceitos para resolvê-los. Entende-se que $G$ armazenou fatos separadamente e os associou através de sinapses, ocorrendo assim a aprendizagem.

Uma das características marcantes de G é a busca pela compreensão, entendendo-se isso como uma repaginação do movimento cerebral de aprender, que ocorreu quando foram utilizadas estratégias didáticas diferenciadas, que proporcionaram diferentes estímulos, modificando os mecanismos de aprendizagem. Isto ocorre quando o SNC altera a sua estrutura, através da plasticidade cerebral, com $G$ pode-se exemplificar nos avanços com os algoritmos das operações com Números Naturais e na resolução de problemas envolvendo o campo aditivo. Percebe-se, nestas situações, a ampliação na sua capacidade de abstração.

Outros exemplos de abstração observam-se quando $G$ deixa de realizar adições, usando o recurso dos dedos para a contagem, quando realiza adições partindo da segunda parcela, deixando de contar a primeira parcela. Também, na subtração, quando inicia a contagem do subtraendo até o resultado desejado, deixando de utilizar o recurso de riscos no papel.

A recente expansão de pesquisas sobre o funcionamento do cérebro e do aprendizado deve fluir diretamente para as salas de aula. O professor deve compreender as diferentes maneiras de aprender e as formas pessoais de aprendizado de todos os alunos. Nesse sentido, as TIC oferecem, através de estímulos multimodais, diferentes recursos didáticos que devem ser agregados à prática dos professores, pois a intervenção pedagógica cognitiva, realizada com $G$, evidencia a importância destes, pois propiciaram um ambiente motivador e facilitador do seu processo de aprendizagem Matemática.

Concorda-se com Relvas (2008), que afirma que o estudo da Neurociência Cognitiva é uma competência necessária para o professor do século XXI, frente ao desafio da inclusão de alunos com NEE nas escolas.

\section{Referências}

AEBH. Associação de Espinha Bífida e Hidrocefalia do Rio de Janeiro. Disponível em: 〈http://www. aebh.org). Acesso em: 5 fev. 2010.

ARAÚJO, L. C. Fundamentos de Neurociência e do Comportamento. Disponível em: 〈http://www.cefala.org/-leoca/neuroscience/neurociencia.pdf >. Acesso em: 5 nov. 2011.

BARNES M., CHANT B. S., LANDRY, S. H. Number processing in neurodevelopmental disordes: spina bifida myelomeningocele. IN: Handbook of mathematical cognition. New York: Camphell, cap. 17, p. 299313, 2005.

BRASIL. Constituição Federal. 1988. Disponível em: 〈http://www.in.gov.br/imprensa:constituição/ conl988br.pdf> Acesso em: 05 ago. 2007. 
Lei no 9.394, 20 de dezembro de 1996. Esclarece as diretrizes e bases da educação nacional. Brasília, DF. 1996. Disponível em: 〈http://www.mec.gov.br/seesp〉 Acesso em: 15 ago. 2007.

BRAVO, J. A. F. Neurociencias y enseñanza de la Matemática: prólogo de algunos retos educativos. Revista Iberoamericana de Educación, Madrid, n. 51/3, p. 1-12, 25 jan. 2010.

COELHO, R.P.S.; KAEFER, H. Resultados da avaliação neuropsicológica. Núcleo de neurologia cognitiva. Porto Alegre: Hospital Moinhos de Vento, 2012.

DENNIS, M.; BARNES M. Mathematic and numeracy in Young adults with Spina Bifida and Hydrocephalus. IN: Developmental neuropsychology. 21(2), p. 141-155. Lawrence Erilbaum Associates, Inc., 2002.

DOMINGUES, M. A. Desenvolvimento e aprendizagem: o que o cérebro tem a ver com isso? Canoas, RS: ULBRA, 2007.

FARINA, J. I. Avaliação de dificuldade de aprendizado. POA: Hospital Moinhos de Vento, 2012.

FERREIRA, F.; DIAS, M.; SANTOS, P. Níveis e tipos de deficiência mental, 2006. Disponível em: ‘http:// edif.blogs.sapo.pt/568.html . Acesso em: 18 mai. 2011.

FIERRO, A. Os alunos com deficiência mental. In: COLL, C. et al. Desenvolvimento psicológico e educação: transtornos de desenvolvimento e necessidades educativas especiais. Porto Alegre: Artmed, v. 3, p. $193-214,2004$.

FIORI, N. As neurociências cognitivas. Petrópolis, RJ: Vozes, 2008.

HOWARD-JONES, P. Neuroscience, learning and technology (14-19). Becta: 2009. Disponível em 〈http:/www.bristol.ac.uk/education/people/academicStaff/edpahj/publications/becta.pdf〉. Acesso em: 15 ago. 2012.

INÁCIO, S. R. L. A importância da neurociências na aprendizagem e educação. Disponível em: < http:// www.artigos.com/artigos/humanas/educacao/a-importancia-da-neurociencia-na-aprendizagem-e-educacao.-5206/artigo/> Acesso em: 6 nov. 2011.

LENT, R. Cem bilhões de neurônios: conceitos fundamentais. Atheneu: São Paulo, 2004.

LEVINE, M. Educação individualizada: motivação e desenvolvimento sob medida para seu filho. Rio de Janeiro: Campus, 2003.

MILHEIRO, I. Promoção da Autonomia Pessoal e Social de Jovens com Deficiência Mental nas Escolas Básicas de $2^{\underline{o}}$ e $3^{\underline{o}}$ ciclo. Disponível em:/http://repositorio.esepf.pt/bitstream/handle/10000/273/PG -EE2009IsabelMilheiro.pdf?sequence=1>. Acesso em: 14 set. 2012.

NIED (Org.). Tutorial do JClic. Disponível em: ‘http://www.scribd.com/Tutorial-do-JCLIC/d/28811507〉. Acesso em: 3 abr. 2010.

OLIVEIRA, M. A. D. Neurofisiologia do comportamento: uma relação entre o funcionamento cerebral e as manifestações comportamentais. Canoas/RS: ULBRA, 1999.

Neurologia básica. Canoas, RS: ULBRA, 2005.

RAMOS, L. F. Conversas sobre números, ações e operações: uma proposta criativa para o ensino da matemática nos primeiros anos. São Paulo: Ática, 2009. 
Contribuições da neurociências para a educação matemática de uma pessoa com necessidades educativas especiais intelectivas

RELVAS, M. P. Fundamentos biológicos da educação. Rio de Janeiro: Wak, 2007.

Neurociência na aprendizagem escolar. Rio de Janeiro: Wak, 2008.

Neurociências e transtornos da aprendizagem: as múltiplas eficiências para uma educação inclusiva. Rio de Janeiro: Wak, 2009a.

Neurociências e educação: potencialidades dos gêneros humanos na sala de aula. Rio de Janeiro: WAK, 2009b.

Neurociência na prática pedagógica. Rio de Janeiro: Wak, 2012.

VYGOTSKY, L. S. A Formação Social da Mente. São Paulo: Martins F

\section{Notas}

${ }^{1}$ Implementar no sentido de desenvolver, aplicar e avaliar.

${ }^{2}$ Fibras que levam impulsos ao córtex (OLIVEIRA, 2005).

${ }_{3}^{3}$ Fibras que trazem respostas elaboradas pelo córtex em direção ao tálamo, hipotálamo, pedúnculo, ponte, bulbo, medula e meio externo (OLIVEIRA, 2005).

${ }^{4}$ Potencial evocativo cognitivo - Condições do exame: vigília. Contagem correta de estímulos-alvo.

${ }^{5}$ O JClic é um programa para a criação, realização e avaliação de atividades educativas multimídia, desenvolvido na plataforma Java. É uma aplicação em software livre, baseado em código aberto. É formado por um conjunto de aplicações informáticas que servem para realizar diversos tipos de atividades educativas (NIED, 2010).

${ }^{6}$ Em alguns dos relógios utilizados no estudo das unidades de tempo, os números estavam representados com essa numeração.

${ }^{7}$ Vygotsky (1984) define como zona de desenvolvimento proximal a distância entre aquilo que a criança pode fazer de forma autônoma (nível de desenvolvimento real) e aquilo que ela realiza em colaboração com os outros elementos do seu grupo social (nível de desenvolvimento potencial). A zona de desenvolvimento proximal define aquelas funções que ainda não amadureceram, mas que estão em processo de maturação.

${ }^{8}$ A motivação externa foi uma preocupação constante das pesquisadoras durante a implementação da SDE. Por esse motivo optou-se por elaborá-la com uma grande gama de ferramentas (material concreto, TIC, atividades no papel, jogos, livros,...) diversificando as sessões de estudo.

\section{Correpondência}

Tania Elisa Seibert - Universidade Luterana do Brasil. Avenida Farroupilha, 8001, São Luís, CEP: 92450900 - Canoas, RS - Brasil

E-mail: taniaseibert@hotmail.com - claudiag1959@yahoo.com.br

Recebido em 11 de janeiro de 2013

Aprovado em 22 de agosto de 2013 
